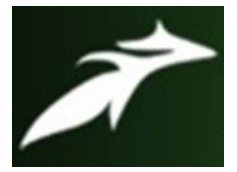

Jenifer Lolita C, International Journal of Advances in Agricultural Science \& Technology,

Vol.9 Issue.1, January-2022, pg. 1-13

ISSN: 2348-1358

\title{
Cloning and Expression Analysis of bZIP Transcription Factor from Finger Millet (Eleusine coracana L.) Under Abiotic Stress Conditions
}

\author{
Jenifer Lolita $C^{*}$ \\ Associate Professor, Department of Botany, Maharani Cluster University, Palace Road, \\ Bengaluru, Karnataka, India \\ DOI: 10.47856/ijaast.2022.v09i01.001
}

\begin{abstract}
Basic leucine zipper (bZIP) transcription factors comprise one of the largest gene families in plants. They play a key role in almost every aspect of plant growth and development and also in biotic and abiotic stress tolerance. In this study, we were attempted to study characterization of bZIP, a transcription factor from a climate smart cereal finger millet (Eleusine coracana L.). Seeds of Eleusine coracana (finger millet) was purchase from local market and were grown under field conditions drought and salt stress conditions. In this study, EcbZIP gene was isolated from finger millet, cloned into DH5a cells, screened by using colony PCR and expression analysis in response to two abiotic stresses was carried out by using $q R T$ PCR. EcbZIP coding DNA sequence and protein sequence were retrieved from NCBI Nucleotide Database and Genpept of Accession number KP033192.1 and AJP67539.1 and validated by using SMART (simple modular architecture tool) Domain Tool. Cloning and expression studies were carried out using standardized molecular biology protocol. Results depicted that EcbZIP transcription factor showed significant upregulation under both salt and drought stress conditions, indicating that it plays an important role in tolerance towards these stresses. In conclusion, expression analysis of bZIP gene from finger millet seed cultivar ML-365 showed 5-fold upregulation to salt stress to drought stress and 8-fold upregulation to salt stress. Hence, it can serve as a candidate gene for improving abiotic stress tolerance and can be helpful in enhancing the crop productivity under stress conditions.
\end{abstract}

Keywords: Finger millet, bZIP transcription factor, Drought stress, Salt stress

\section{Introduction}

Agricultural production and quality are adversely affected by a broad range of abiotic stresses including drought, salinity, heat, and cold. Especially when these stresses occur in combination, it can have devastating effects on plant growth and productivity. It is estimated that more than $50 \%$ of worldwide yield loss for major crop are caused by abiotic stresses. ${ }^{1-3}$ According to the current climate prediction models, the deterioration of global climate will inevitably cause an increased frequency of drought, heat wave, and salinization. This means that agricultural productivity will face a greater challenge in fighting against environmental stresses. Meanwhile, the growing world population will reach close to ten billion by the year 2050 and the almost two times of current agricultural productivity is needed to feed the large population. ${ }^{4}$ Moreover, such a tremendous increase of crop productivity must be achieved with no increase in arable land and in the face of multiple environmental stresses. 


\section{$\vec{x}$ \\ Jenifer Lolita C, International Journal of Advances in Agricultural Science \& Technology, \\ Vol.9 Issue.1, January-2022, pg. 1-13}

ISSN: 2348-1358

Impact Factor: 6.846

NAAS Rating: 3.77

Many scholars and experts worldwide have reached a consensus that breeding stress-tolerant crops with higher yields and improved qualities against multiple environmental stresses is an effective strategy, as well as one of the greatest challenges faced by modern agriculture. ${ }^{5-7}$ Two main approaches have been employed to this process. One is traditional breeding methods which often bring about unpredictable results. Another is modern transgenic technology by introducing novel exogenous genes or altering the expression levels of endogenous genes to improve stress tolerance. Since conventional breeding approaches have marginal success due to the complexity of stress tolerance traits, the transgenic approach is now being popularly used to develop transgenic crops tolerant to abiotic stresses. ${ }^{8}$ Therefore, deciphering the molecular mechanisms by which plants perceive and transduce stress signals to cellular machinery to initiate adaptive responses is an essential prerequisite for identification of the key genes and pathways to engineer stress-tolerant crop plants. ${ }^{9-11}$

As one of the most important regulators, TFs function as terminal transducers and directly regulate the expression of an array of downstream genes by interacting with the specific cis-elements in their promoter region. ${ }^{12}$ In the last few decades, considerable research has been conducted to identify and characterize various TFs involved in plant abiotic stress responses either in abscisic acid (ABA)-dependent pathway or ABAindependent pathway, three such TF families are $A P 2 / E R F, M Y B$ and $W R K Y .^{13,14}$

The degree of susceptibility to abiotic stresses varies from species to species. ${ }^{16}$ Finger millet is a highly productive crop that can thrive under a variety of harsh environmental conditions, and is also organic by default. It can be grown on low fertility soils and is not dependent on the use of chemical fertilizers, hence, is a boon for the vast arid and semi-arid regions. ${ }^{17}$ The different genotypes of finger millet have genes for early and vigorous growth, large panicle size, increased finger number and branching as well as high-density grains. Some of the genotypes are water-efficient with elevated carbon dioxide fixation rates and minimal leaf area and hence could perform extraordinary well in semi-arid climates. It is also known to be one of the most efficient utilizers of nitrogen. ${ }^{18}$ Finger millet seeds can resist storage pests for as long as 10 years, ensuring round the year food supply or even during a crop failure, that has earned it the popular name of 'famine crop. ${ }^{19}$

Though finger millet is considered to be generally abiotic stress tolerant, even then there is a need to identify newer sources of stress tolerance in this crop that can be used for crop improvement programs. Assessing patterns of genetic diversity in terms of both abiotic and biotic stress tolerance in finger millet germplasm collections could be very critical. A large number of finger millet accessions have been preserved in various national and international GenBanks in Asian, African, and European countries as well as USA. India has the largest collection of finger millet germplasm followed by Ethiopia. ${ }^{20}$ There could be immense morphological and genetic diversity among finger millet accessions or their core collections. Molecular markers could be used to characterize functional diversity in this crop. $^{21}$ Calcium dynamics, ${ }^{22}$ tryptophan accumulation and association mapping, ${ }^{23,24}$ and disease resistance ${ }^{25}$ have been characterized using molecular markers. However, characterization of abiotic stress tolerance in finger millet using molecular markers is yet very limited and offers an opportunity of exploring the vast collections of wild and cultivated accessions of this crop. Therefore, in the current we attempted to study characterization of bZIP, a transcription factor from a climate smart cereal finger millet (Eleusine coracana L.).

\section{Materials and Methods}

\subsection{Plant germination and stress treatment}

Seeds of Eleusine coracana (finger millet) cultivar ML-365 was purchased from local market and were grown under field conditions. After 10 days of growth saplings were transferred to quarter strength Hoaglands media in order to impose drought and salt stress. Drought stress was stimulated by withholding water and for salt stress was imposed by adding $200 \mathrm{mM} \mathrm{NaCl}$ to the quarter strength Hoaglands media and grown hydroponically for 24hours. After the stress treatment, 24hours control and stress exposed tissues were harvested and stored at $-80^{\circ} \mathrm{C}$ for further analysis. 


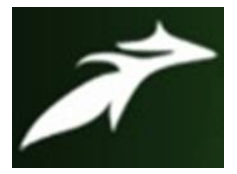

Jenifer Lolita C, International Journal of Advances in Agricultural Science \& Technology,

Vol.9 Issue.1, January-2022, pg. 1-13

ISSN: 2348-1358

Impact Factor: 6.846

NAAS Rating: 3.77

\subsection{Isolation and amplification of bZIP by PCR \\ 2.2.1 Isolation of total RNA}

The total RNA was isolated by modified Chomczynski method using RNA Iso plus (TAKARA). ${ }^{26}$

\subsection{2 cDNA synthesis using total RNA}

The total RNA template was converted to complementary DNA (cDNA) by reverse transcription with total RNA using iScript cDNA Synthesis Kit for Reverse Transcriptase PCR (BIO-RAD) according to manufacturer's instructions. cDNA concentration was checked using Nanodrop2000 (ThermoScientific).

\subsubsection{Sequence retrieval and primer designing}

EcbZIP coding DNA sequence and protein sequence were retrieved from NCBI Nucleotide Database and Genpept of Accession number KP033192.1 and AJP67539.1 and validated by using SMART (simple modular architecture tool) Domain Tool. For EcbZIP sequence primers were designed using Primer3 plus Software (http://bioinfo.ut.ee/primer3-0.4.0/) with the following parameters - Forward and Reverse primers of 26bp, 5055\% GC content, Tm of 60.13 and 59.92 respectively. The restriction sites were inserted in both forward and reverse primers at 5'end for BamHI (GGATCC) and XhoI (CTCGAG) restriction enzymes along with 4bp sitting sequence.

\subsection{Molecular cloning \\ 2.3.1 Competent cell preparation}

The DH5 $\alpha$ cells were grown overnight on LB plate and moderately sized single colonies of DH5 $\alpha$ were picked and inoculated into LB media followed by incubation in shaker $\sim 150 \mathrm{rpm}$ at $37^{\circ} \mathrm{C}$, OD at 600 was measured after every hour to get the 0.2-0.4 OD cells were immediately transferred on ice when it reached 0.4 OD and chilled the culture for 30 minutes with occasional mixing, then the cells were harvested by centrifugation at $3000 x g$ for 15 minutes at $4^{\circ} \mathrm{C}$, the pellet was gently resuspended in ice cold $\mathrm{MgCl}_{2}[100 \mathrm{mM}]$ and was centrifuged at $2000 \mathrm{Xg}$ for 15 minutes at $4{ }^{\circ} \mathrm{C}$, then the pellet was resuspended in ice cold $\mathrm{CaCl}_{2}[100 \mathrm{mM}]$ and kept on ice for 20 minutes and was again centrifuged at $2000 \mathrm{Xg}$ for 15 minutes at $4^{\circ} \mathrm{C}$. The pellet was resuspended in small volume of ice cold $85 \mathrm{mM} \mathrm{CaCl}_{2}, 15 \%$ glycerol [v/v] and was centrifuged at $1000 \mathrm{Xg}$ for 15 min at $4{ }^{\circ} \mathrm{C}$. The pellet was resuspended in small amount of ice cold $85 \mathrm{mM} \mathrm{CaCl}_{2}, 15 \%$ glycerol[v/v] followed by aliquots of $50 \mathrm{ul}$ into sterile vials and was stored in $-80^{\circ} \mathrm{C}$ freezer.

\subsubsection{Plasmid isolation}

Plasmid DNA was isolated from overnight grown culture of E. coli harboring pET28a (+) by alkaline lysis method. ${ }^{27}$

\subsubsection{Gel elution of bZIP and pet28 USING Gene Jet extraction kit}

DNA was extracted from the gel using centrifuge Step Procedure using Gene Jet Purification Kit according to manufacturer's instructions.

\subsubsection{Restriction Enzyme double digestion of vector and insert}

Purified plasmid and EcbZIP PCR amplicon were subjected to restriction double digestion using BamHI and XhoI restriction enzymes simultaneously. In each case the reaction was setup as follows using 10X NEB buffer. HindIII was heat inactivated at $80^{\circ} \mathrm{C}$ for 20 minutes but BamH1-HF cannot be heat inactivated thus it was inactivated by adding 6X NEB purple gel loading dye. This RE double digested mixture was run on agarose gel and then eluted for Ligation. 


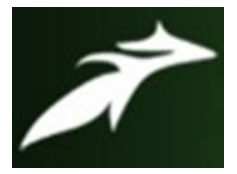

Jenifer Lolita C, International Journal of Advances in Agricultural Science \& Technology, Vol.9 Issue.1, January-2022, pg. 1-13

ISSN: 2348-1358

Impact Factor: 6.846

NAAS Rating: 3.77

\subsubsection{Ligation}

The restriction digested plasmid and insert (EcbZIP) were gel eluted using Gene JET purification Kit and was used for ligation in the ratio 3:1(insert: vector). The reaction was carried out using T4 DNA ligase (Thermo Scientific) and its $10 \mathrm{X}$ buffer at $22^{\circ} \mathrm{C}$ overnight. This mixture was taken for Transformation.

\subsection{Transformation of plasmid carrying bZIP gene into dh5 $\alpha$ competent cells}

\section{Setup for transformation}

\begin{tabular}{|l|l|l|}
\hline \multicolumn{1}{|c|}{ Components } & Vial 1 & Vial 2 \\
\hline Competent cells & $100 \mathrm{ul}$ & $100 \mathrm{ul}$ \\
\hline Ligation mixture & $5 \mathrm{ul}$ & - \\
\hline Control mixture & - & $5 \mathrm{ul}$ \\
\hline
\end{tabular}

This mixture was incubated for 30 minutes on ice followed by a brief 45 second heat shock at $42^{\circ} \mathrm{C}$ and immediately placed on ice for 2 minutes. 900ul of LB broth was added and was incubated for 1hour at $37^{\circ} \mathrm{C}$ in shaker incubator $(150 \mathrm{rpm})$. After incubation it was plated on agar plate containing Kanamycin and was incubated overnight at $37^{\circ} \mathrm{C}$. (Table 2)

\subsection{Colony PCR}

From the transformed culture plate three isolated colonies were picked using a sterile tooth pick and swirled in minimal amount of distilled water taken in different vials. The cells were lysed with a short heating step. $2 \mathrm{ul}$ of this lysed cell solution was used for colony PCR in order to validate the presence or absence of transformed colonies. Controls used in this experiment were DH5 $\alpha$ competent cells and DH5 $\alpha$ competent cells containing pET28a (+) as negative controls in order to check the gene specific primers were complementary to bacterial genomic DNA or to the plasmid DNA. A no template control was also done as another negative control.

\section{6. qRT PCR}

To study the drought and salt expression levels of bZIP, total RNA was isolated from drought and salt stress induced tissues of finger millet genotype; and was converted to cDNA as described earlier. Using bZIP genespecific primers, expression profiling was carried out in all the tissues. Real-time PCR (qPCR) was carried out using the 2x Brilliant III SYBR Green qPCR Master Mix, Agilent according to the manufacturer's instructions using CFX96 Real-Time System. (Table 1)

Table 1: Reaction composition of qRT PCR

\begin{tabular}{|l|c|}
\hline \multicolumn{1}{|c|}{ Component } & Volume per reaction \\
\hline cDNA & $1 \mathrm{ug}$ \\
\hline $\begin{array}{l}\text { 2x Brilliant III SYBR Green QPCR Master Mix with } \\
\text { High ROX }\end{array}$ & $10 \mathrm{ul}$ \\
\hline Forward Primer & $1 \mathrm{ul}$ \\
\hline Reverse Primer & $1 \mathrm{ul}$ \\
\hline Total Volume made up with nuclease free water & $20 \mathrm{ul}$ \\
\hline
\end{tabular}

The CYP gene was used as an internal control, the amplification profile used for qPCR was $95{ }^{\circ} \mathrm{C}$ for 2-min initial denaturation followed by 30 cycles of $95^{\circ} \mathrm{C}$ for 3 mins, $95^{\circ} \mathrm{C}$ for $13 \mathrm{~s}, 50^{\circ} \mathrm{C}$ for $30 \mathrm{~s}$, and $55^{\circ} \mathrm{C}$ for $30 \mathrm{~s}$. 


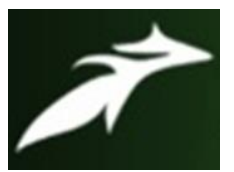

Jenifer Lolita C, International Journal of Advances in Agricultural Science \& Technology,

Vol.9 Issue.1, January-2022, pg. 1-13

ISSN: 2348-1358

Impact Factor: 6.846

NAAS Rating: 3.77

All samples were amplified in duplicates and the mean value was considered. The normalized transcript expression was quantified using the $2^{-\Delta \Delta \mathrm{CT}}$ method and presented as fold change over control. ${ }^{28}$

\section{Results and Discussion}

\subsection{Total RNA isolation}

Total RNA was isolated from 10 days old saplings. The concentration of the total RNA was determined using Nanodrop 2000 and was found to be $250 \mathrm{ug} / \mathrm{ul}$. To check the quality of the total RNA before proceeding for further steps, RNA was run on $1 \%$ agarose gel which is depicted in the Figure 1. Three bands were obtained which represents $28 \mathrm{~s}$ rRNA, $18 \mathrm{~s}$ rRNA and 5.8s rRNA indicating the total RNA isolated was intact and had not undergone degradation. Total RNA was taken as template for the synthesis of cDNA (complementary DNA) by reverse transcriptase. The concentration of the cDNA was determined using Nanodrop 2000 and was found to be 100ug/ul (Figure 1).

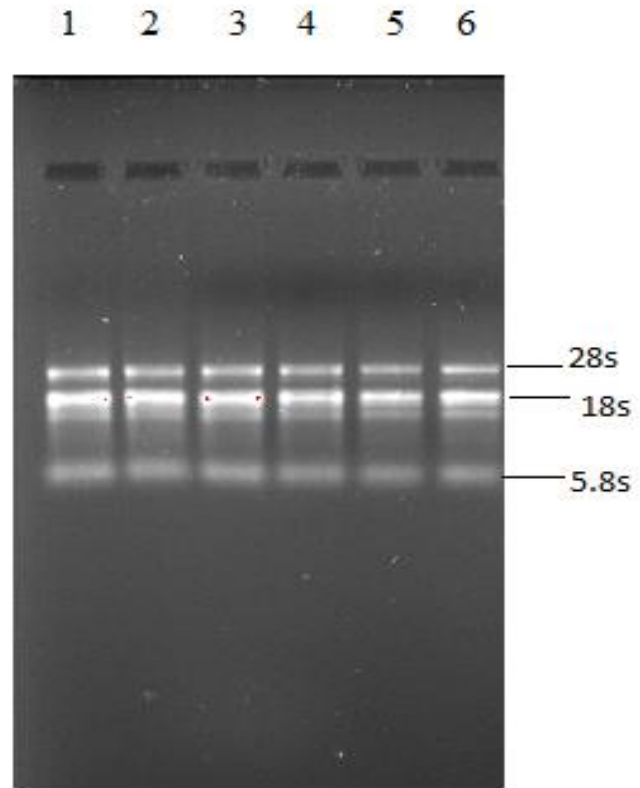

Figure 1: Isolated RNA from Finger Millet (ML 365). Lane 1 to 6: Isolated RNA; First band from top represents $28 \mathrm{~s}$ rRNA, second band 18s rRNA and third band $5.8 \mathrm{~s}$ rRNA.

\subsection{Primer designing}

The coding DNA sequence and protein sequence of EcbZIP, obtained from NCBI Nucleotide data base and Genepept were:

\section{Coding DNA sequence}

AATATCCCAATCGAGCTACATGGACGCGGACTTCTTCGCTGACCTCGACTTTGTCGCCCTCCTCGCATCC TTCTCCGGCGAGCCCGCCGCCGTCTCCGATATTATCATCCCCTCCCCTCCTCCGCCGTCGCCGCCGGCGC GCGATGCGGAGGCGGGGTCGCCGGAGTCAGTGACTTCCCGGTCGAGCCCTCCGGCGGAGGCCCTATCGGA GATCGAGAGGTTCCTGATGGAGGAGGGGGAGGCGGAGGGCGACGGGGCGGTGGAAGGGATCAGCGTGGAG GAATTCTTCGACGCGCTGTACGACGGCGGGGAGGAGAAAGAGAAGGAGAGCGAGGCGGGCGGGAGCACGG ATTCGGGCTCCGGCAGGGAGGAGGAGGTTGCGACGCCGGAGGCGGAGAAGTTGGAGGTGGATGGCGATGA CCCCGTCAGCAAGAAGAAGAGGAGGCAAATGAGGAACAGGGATTCTGCCATGAAATCGAGGGAGAGGAAG AAGTTATATGTAAAGGAATTGGAGACGAAGAGCAAGTATTTGGAGGCAGAGTGCCGCCGTCTCAGCTACG CACTCCAGTGCTACGCAGCTGAGAACATGACACTGCGCCAGAGCTTGCTGAAGGATAGGCCTGTTGGTGC 


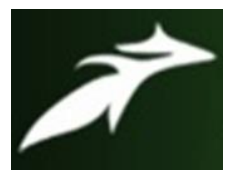

Jenifer Lolita C, International Journal of Advances in Agricultural Science \& Technology, Vol.9 Issue.1, January-2022, pg. 1-13

ISSN: 2348-1358

Impact Factor: 6.846

NAAS Rating: 3.77

TCCCACAGCCATGCAGGAGTCTGCCGTACTCACGGAAACCCTGCCGATGGTTTCCCTGCTTTGGCTGGTG AGCATCGTGTGCCTATTCCTAATGCCCGGTCTACCCAACCCAAGCTCAGCTGCTCCAAGAAGCAGCGGGA GAGATCTCGTGACGGTAGCCGGAAAGCCAAGCAGTGAAAACCCAGAGACACTGGACCTCATCCTCCATGG AAGGCGTTGCAAGGGCACAAGGGCGAAGATCAAGCTATCTACCTTACCGTTTCATGCTGCAGCAGCTTGT TAGGCTAGGCTTATCATGATCTGTAGTAGTCGCCTTTCCAAGGCTTAGCATGCCTATGGCATGTGCATCC ATGGAGTATGTACCTATTTTTTTTGTTCTTTTTTCCTCCTGATTTATGATCCCATCGTACCCAGAGTAGT TTTCAAATCTGGTTTGTGTTATGTCTTTTCGTCTCGCTGCTCCAGGATCGAAGAATAGTCGGGACCAAAA CAGTGAAGTATGAAGCTTGGACCTATAGTCATCTATAAAATCTTCGATTATATGCAAAAAAAA

\section{Protein sequence}

>AJP67539.1 bZIP transcription factor [Eleusine coracana]

MDADFFADLDFVALLASFSGEPAAVSDI I IPS PPPP SP PARDAEAGS PESVTSRSSPPAEALSEIERFLM EEGEAEGDGAVEGISVEEFFDALYDGGEEKEKESEAGGSTDSGSGREEEVATPEAEKLEVDGDDPVSKKK RRQMRNRDSAMKSRERKKLYVKELETKSKYLEAECRRLSYALQCYAAENMTLRQSLLKDRPVGAPTAMQE SAVLTETLPMVSLLWLVS IVCLFLMPGLPNPS SAAPRSSGRDLVTVAGKP SSENPETLDLI LHGRRCKGT RAKIKLSTLPFHAAAAC

Validation of Protein sequences using SMART Domain Tool

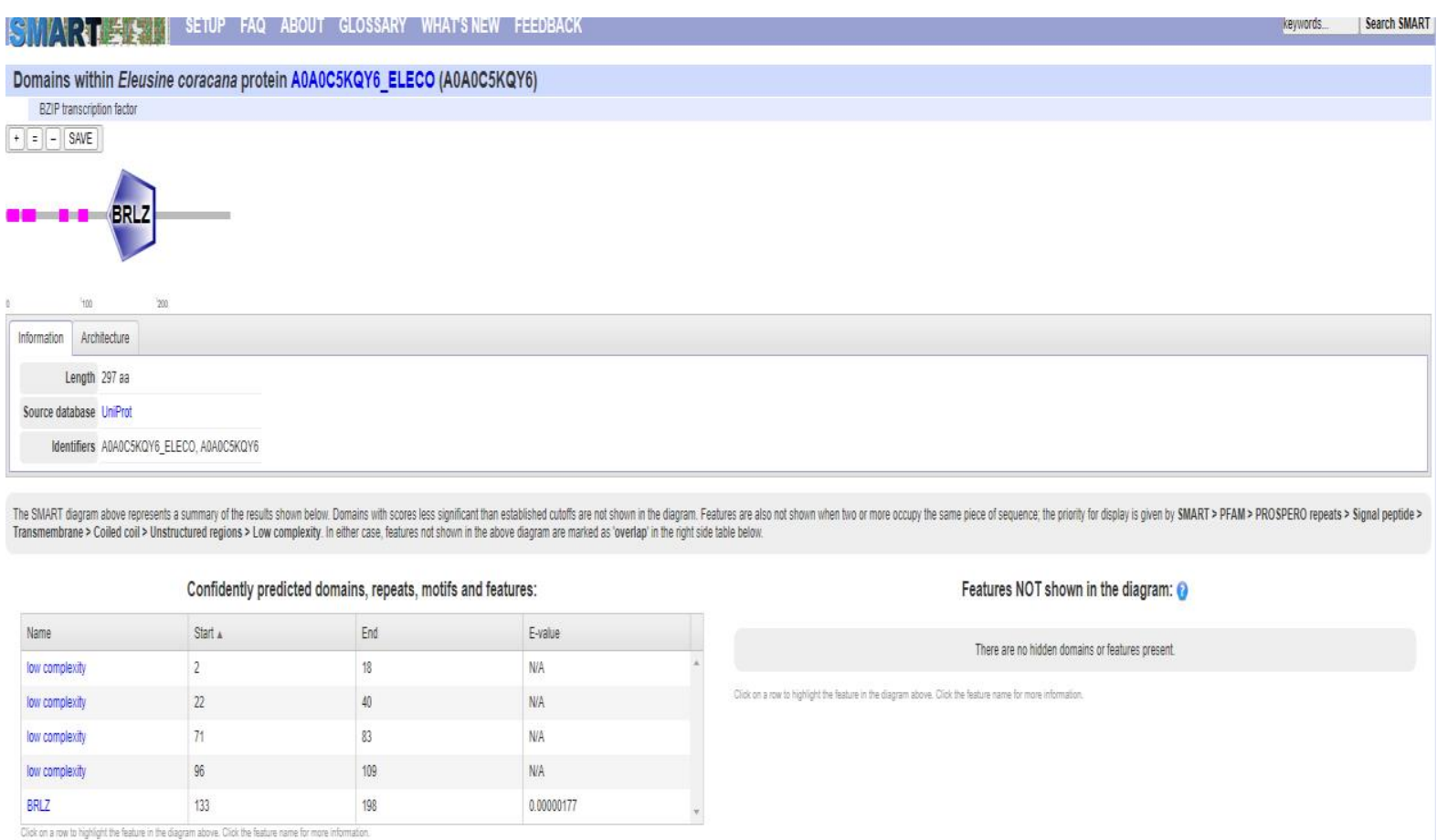




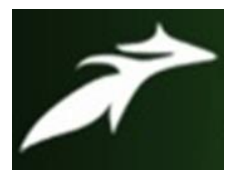

Jenifer Lolita C, International Journal of Advances in Agricultural Science \& Technology,

Vol.9 Issue.1, January-2022, pg. 1-13

ISSN: 2348-1358

Impact Factor: 6.846

NAAS Rating: 3.77

Using primer3 plus software specific primers for EcbZIP were design:

Table 2: Primer for EcbZIP

\begin{tabular}{|l|l|}
\hline $\begin{array}{l}\text { Forward PRIMER having BamH1 } \\
\text { restriction site }\end{array}$ & 5'atatGGATCCCCGTCAGCAAGAAGAAGAGG 3' \\
\hline $\begin{array}{l}\text { Reverse PRIMER having Xho1 } \\
\text { restriction site }\end{array}$ & 5'atatCTCGAGGGGCATTAGGAATAGGCACA 3, \\
\hline
\end{tabular}

\subsection{PCR amplification}

In order to amplify bZIP gene, cDNA was used as template and PCR reaction was set up with gene specific forward and reverse primers along with an NTC. The amplified mixture was run on 1.5\% agarose gel along with $100 \mathrm{bp}$ and $1 \mathrm{~kb}$ ladder (Figure 2). A single band was obtained. (Figure 2) The amplified mixture was eluted from gel by using ThermoScientific Gene JET Extraction Kit.

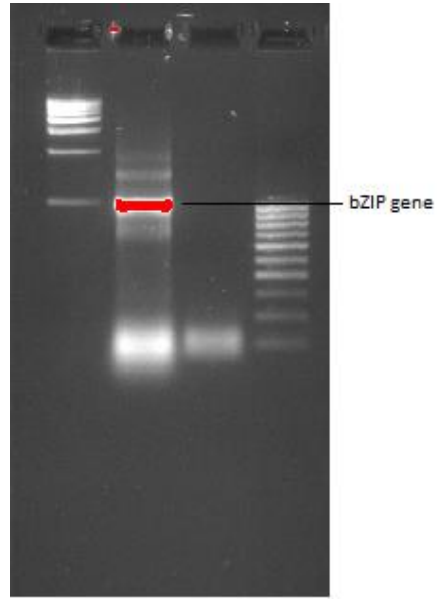

Figure 2: Amplified bZIP gene. Lane 1: 1kb ladder; Lane 2: bZIP gene, Lane 3 NTC; Lane 4: 100bp ladder

\subsection{Plasmid isolation}

To clone bZIP gene, pET28a plasmid was isolated by alkali lysis method and purified by phenol chloroform isoamyl alcohol. After isolation, the dissolved plasmid was given RNase, a treatment to remove RNA. The quality of the plasmid was determined by agarose gel electrophoresis. The plasmid was resolved into 3 bands representing linear, circular and supercoiled DNA (Figure 3). The concentration of purified plasmid determined by Nanodrop was found to be 200ug/ul. 


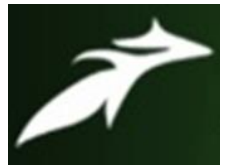

Jenifer Lolita C, International Journal of Advances in Agricultural Science \& Technology,

Vol.9 Issue.1, January-2022, pg. 1-13

ISSN: 2348-1358

Impact Factor: 6.846

NAAS Rating: 3.77

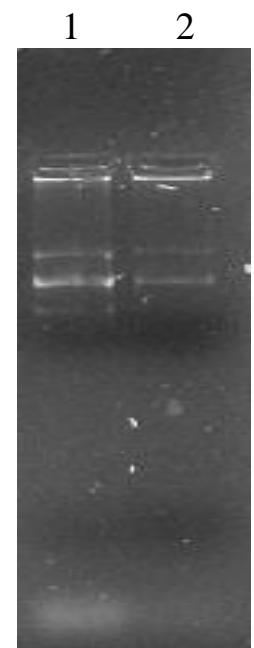

Figure 3: Pet28a plasmid on 1\% agarose gel. Lane 1 and 2: pET28a plasmid DNA showing linearised, circular and supercoiled DNA bands

\subsection{Restriction digestion of purified plasmid and EcbZIP gene}

The purified plasmid and bZIP gene were digested with Xho1 and BamH1 to create cohesive ends. The digested plasmid mixture was run on $1 \%$ agarose gel to check for complete digestion. The plasmid was linearized and showed single band of 5.3kbp (Figure 4).

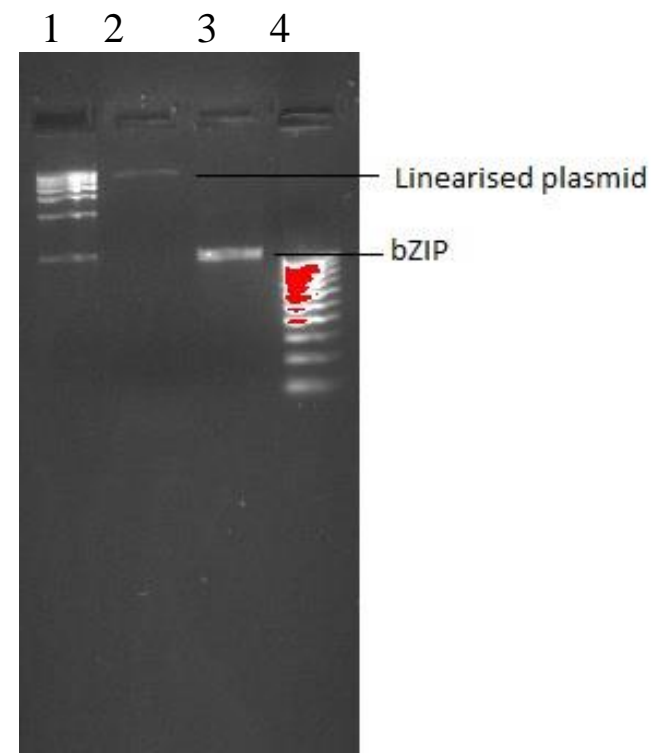

Figure 4: Restriction digestion of pET28a and bZIP for Ligation; Lane 1; $1 \mathrm{~kb}$ ladder; Lane 2; Linearised plasmid; Lane3; Linearised bZIP; Lane 4; 100bp Ladder 


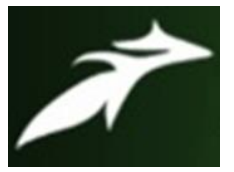

Jenifer Lolita C, International Journal of Advances in Agricultural Science \& Technology,

Vol.9 Issue.1, January-2022, pg. 1-13

ISSN: 2348-1358

Impact Factor: 6.846

NAAS Rating: 3.77

\subsection{Cloning of EcbZIP into DH5 $\alpha$ cells}

The linearized plasmid and the digested bZIP gene were ligated using T4 DNA ligase and transformed into $E$. coli host DH5 $\alpha$. The transformed culture was plated on kanamycin containing LB agar and incubated at $37^{\circ} \mathrm{C}$ overnight and figure 5 shows the positive control.

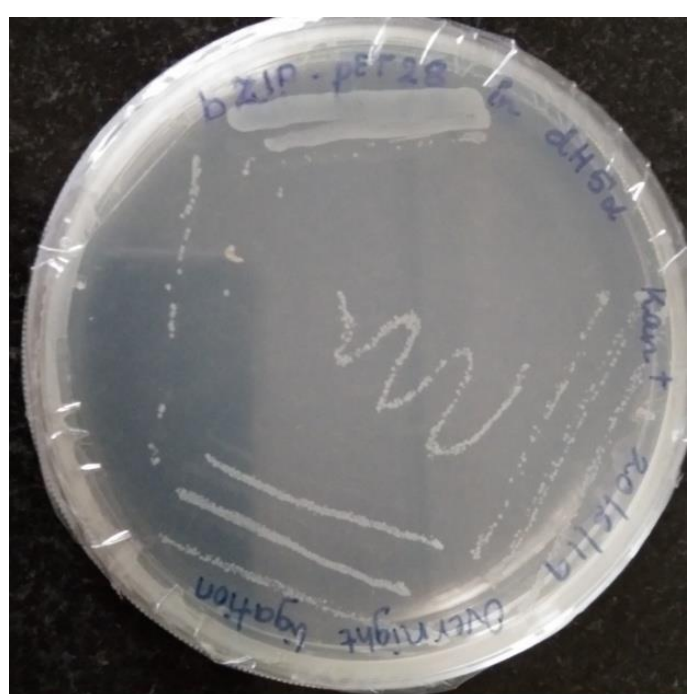

Figure 5: Positive control: The transformed colonies after cloning on LB agar plate containing Kanamycin

To check the efficiency of competent cells it was grown on LB agar plate containing Kanamycin. The competent cells were plated on LB agar in the presence and absence of kanamycin and was incubated overnight at $37^{\circ} \mathrm{C}$ as shown in figure 6 and 7 respectively.

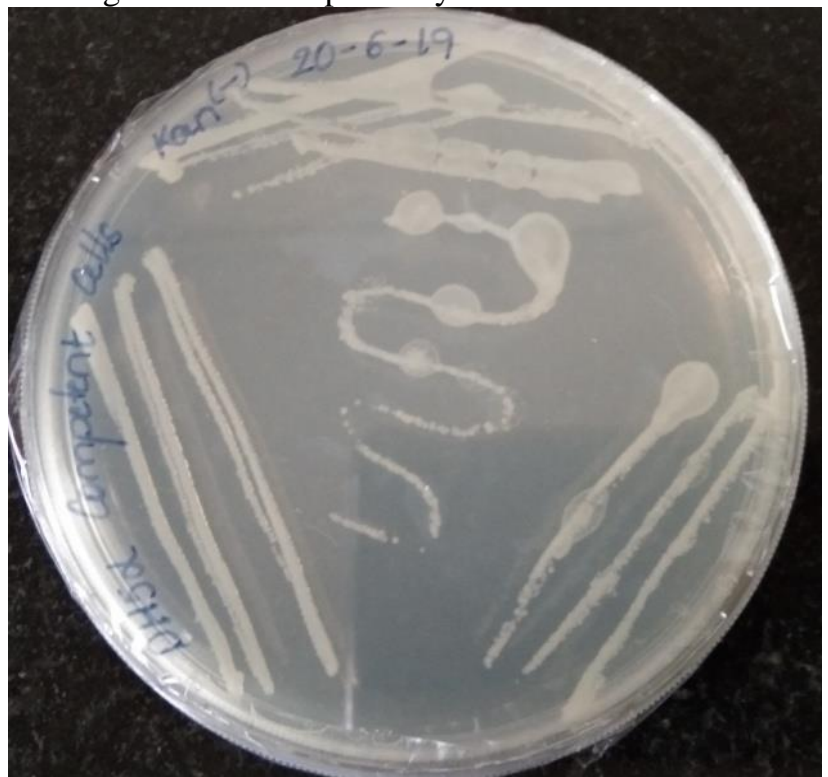

Figure 6 : Competent cells grown without Kanamycin 


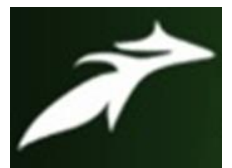

Jenifer Lolita C, International Journal of Advances in Agricultural Science \& Technology,

Vol.9 Issue.1, January-2022, pg. 1-13

ISSN: 2348-1358

Impact Factor: 6.846

NAAS Rating: 3.77

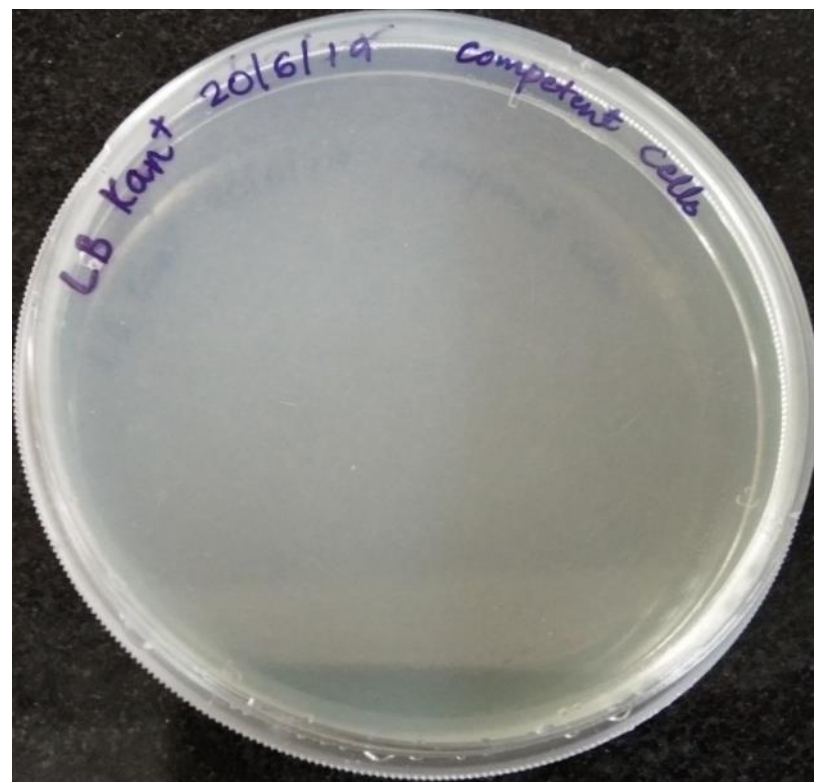

Figure 7: Competent cells grown with Kanamycin

\subsection{Screening of recombinant plasmids by colony PCR}

Colony PCR is a convenient high through put method for determining the presence and absence of insert DNA in Plasmid grown up on antibiotic containing media following transformation, by using gene specific primers. Colony PCR was carried out by picking three colonies from transformed culture plate and run on agarose gel to check for the bZIP amplicon. Gel was visualized using BioRad gel documentation unit. Out of three colonies picked in this experiment two were confirmed to contain insert (Figure 8).

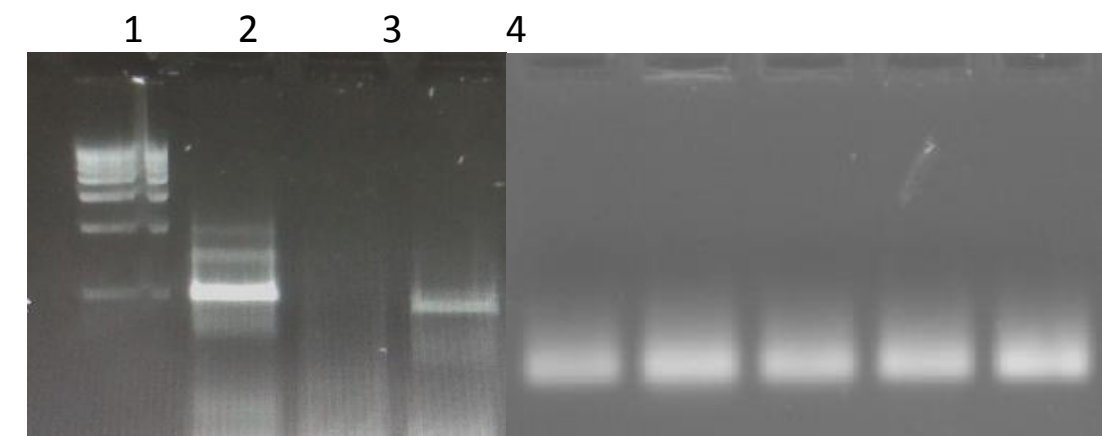

Figure 8: Colony PCR Gel; Lane 1; 100bp Ladder; Lane 2 and 4 showing positive clones; Lane3 negative clone

\subsection{Differential expression analysis of bZIP}

The expression pattern of EcbZIP under drought and salt stress was investigated by qPCR. EcbZIP showed a 5fold upregulation under drought and an 8 -fold upregulation under salt stress. It was found to be up regulated in both drought and salt stress (Figure 9 and Table 3). 


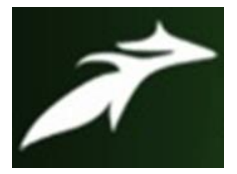

Jenifer Lolita C, International Journal of Advances in Agricultural Science \& Technology, Vol.9 Issue.1, January-2022, pg. 1-13

ISSN: 2348-1358

Impact Factor: 6.846

NAAS Rating: 3.77

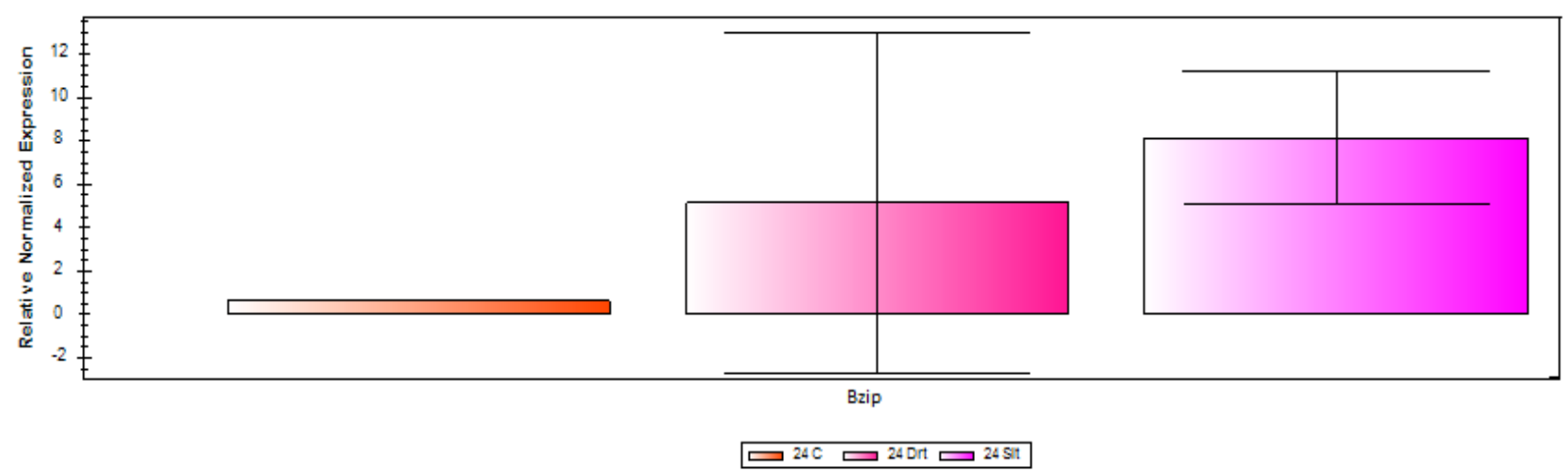

Figure 9: Relative normalised expression of EcbZIP under salt and drought conditions

Table 3: Quantification data showing expression of bZIP under salt and drought stress conditions

\begin{tabular}{|c|c|c|c|c|}
\hline Target & Sample & Expression & Expression SEM & Mean Cq \\
\hline CYP & $24 \mathrm{C}$ & N/A & N/A & 27.94 \\
\hline CYP & $24 \mathrm{Drt}$ & N/A & N/A & 30.44 \\
\hline CYP & $24 S l t$ & N/A & N/A & 30.97 \\
\hline bZIP & $24 \mathrm{C}$ & 0.62850 & 0.00000 & 35.12 \\
\hline bZIP & $24 \mathrm{Drt}$ & 5.14503 & 7.82143 & 34.58 \\
\hline bZIP & $24 \mathrm{Slt}$ & 8.14513 & 3.07544 & 35.98 \\
\hline
\end{tabular}

Transcription factors of the bZIP family control important processes in all eukaryotes. In plants, bZIPs are regulators of many central developmental and physiological processes including abiotic and biotic stress responses. ${ }^{2}$ bZIP TFs have been reported to be excellent candidate genes for the improvement of stress tolerance in crop plants, ${ }^{24}$ and several bZIP transcription factor genes have been cloned from Arabidopsis, rice, soybean, maize etc., and found to participate in plant abiotic stress-response. ${ }^{4,23,25}$ In line with these results, we carried the expression profiling of EcbZIP under abiotic stress and found that the EcbZIP transcription factor showed significant upregulation under both salt and drought stress conditions, indicating that it plays an important role in tolerance towards these stresses.

\section{Conclusion}

In conclusion, expression analysis of bZIP gene from finger millet seed cultivar ML-365 showed 5-fold upregulation to salt stress to drought stress and 8-fold upregulation to salt stress. Hence, it can serve as a candidate gene for improving abiotic stress tolerance and can be helpful in enhancing the crop productivity under stress conditions. 


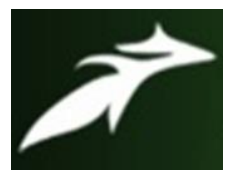

Jenifer Lolita C, International Journal of Advances in Agricultural Science \& Technology, Vol.9 Issue.1, January-2022, pg. 1-13

ISSN: 2348-1358

Impact Factor: 6.846

NAAS Rating: 3.77

\section{References}

1. Shao HB, Chu LY, Jaleel CA, Manivannan P, Panneerselvam R, Shao MA. Understanding water deficit stressinduced changes in the basic metabolism of higher plants-biotechnologically and sustainably improving agriculture and the ecoenvironment in arid regions of the globe. Critical reviews in biotechnology. 2009;29(2):131-51.

2. Ahuja I, de Vos RC, Bones AM, Hall RD. Plant molecular stress responses face climate change. Trends in plant science. 2010;15(12):664-74.

3. Lobell DB, Schlenker W, Costa-Roberts J. Climate trends and global crop production since 1980. Science. 201;333(6042):616-20.

4. Bengtsson M, Shen Y, Oki T. A SRES-based gridded global population dataset for 1990-2100. Population and Environment. 2006;28(2):113-31.

5. Takeda S, Matsuoka M. Genetic approaches to crop improvement: responding to environmental and population changes. Nature Reviews Genetics. 2008;9(6):444-57.

6. Newton AC, Johnson SN, Gregory PJ. Implications of climate change for diseases, crop yields and food security. Euphytica. 2011;179(1):3-18.

7. Liu JH, Peng T, Dai W. Critical cis-acting elements and interacting transcription factors: key players associated with abiotic stress responses in plants. Plant molecular biology reporter. 2014;32(2):303-17.

8. Yamaguchi T, Blumwald E. Developing salt-tolerant crop plants: challenges and opportunities. Trends in plant science. 2005;10(12):615-20.

9. Swatismita R, Dansana PK, Avantika B, Jitender C, Sanjay K, Khurana JP, Tyagi AK. Emerging trends in functional genomics for stress tolerance in crop plants. Plant stress biology: from genomics to systems biology. 2009:37-63.

10. Heidarvand L, Amiri RM. What happens in plant molecular responses to cold stress?. Acta Physiologiae Plantarum. 2010 May 1;32(3):419-31.

11. Sanchez DH, Pieckenstain FL, Szymanski J, Erban A, Bromke M, Hannah MA, Kraemer U, Kopka J, Udvardi MK. Comparative functional genomics of salt stress in related model and cultivated plants identifies and overcomes limitations to translational genomics. PloS one. 2011;6(2):e17094.

12. Yamaguchi-Shinozaki K, Shinozaki K. Transcriptional regulatory networks in cellular responses and tolerance to dehydration and cold stresses. Annu. Rev. Plant Biol. 2006; 57:781-803.

13. Vinocur B, Altman A. Recent advances in engineering plant tolerance to abiotic stress: achievements and limitations. Current opinion in biotechnology. 2005;16(2):123-32.

14. Umezawa T, Fujita M, Fujita Y, Yamaguchi-Shinozaki K, Shinozaki K. Engineering drought tolerance in plants: discovering and tailoring genes to unlock the future. Current opinion in biotechnology. 2006;17(2):113-22.

15. Golldack D, Lüking I, Yang O. Plant tolerance to drought and salinity: stress regulating transcription factors and their functional significance in the cellular transcriptional network. Plant cell reports. 2011;30(8):1383-91.

16. Dida MM, Devos KM. Finger millet. InCereals and millets 2006:333-343.

17. Gull A, Jan R, Nayik GA, Prasad K, Kumar P. Significance of finger millet in nutrition, health and value added products: a review. Magnesium (Mg). 2014;130(32):120.

18. Gupta SM, Arora S, Mirza N, Pande A, Lata C, Puranik S, Kumar J, Kumar A. Finger millet: a "certain" crop for an "uncertain" future and a solution to food insecurity and hidden hunger under stressful environments. Frontiers in plant science. 2017; 8:643.

19. Mgonja MA, Lenne JM, Manyasa E, Sreenivasaprasad SE. Finger millet blast management in East Africa Creating opportunities for improving production and utilization of finger millet. 2007.

20. Dwivedi SL, Upadhyaya HD, Senthilvel S, Hash CT, Fukunaga K, Diao X, Santra D, Baltensperge D, Prasad M. Millets: genetic and genomic resources. 2012.

21. Kumar S, Rajendran K, Kumar J, Hamwieh A, Baum M. Current knowledge in lentil genomics and its application for crop improvement. Frontiers in plant science. 2015; 6:78.

22. Yadav S, Gaur VS, Jaiswal JP, Kumar A. Simple sequence repeat (SSR) analysis in relation to calcium transport and signaling genes reveals transferability among grasses and a conserved behavior within finger millet genotypes. Plant systematics and evolution. 2014;300(6):1561-8.

23. Babu BK, Agrawal PK, Pandey D, Kumar A. Comparative genomics and association mapping approaches for opaque 2 modifier genes in finger millet accessions using genic, genomic and candidate gene-based simple sequence repeat markers. Molecular breeding. 2014a;34(3):1261-79.

24. Babu BK, Agrawal PK, Pandey D, Jaiswal JP, Kumar A. Association mapping of agro-morphological characters among the global collection of finger millet genotypes using genomic SSR markers. Molecular biology reports. 2014b;41(8):5287-97. 


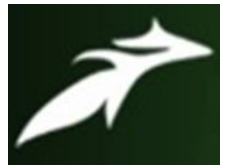

Jenifer Lolita C, International Journal of Advances in Agricultural Science \& Technology,

Vol.9 Issue.1, January-2022, pg. 1-13

ISSN: 2348-1358

Impact Factor: 6.846

NAAS Rating: 3.77

25. Babu BK, Dinesh P, Agrawal PK, Sood S, Chandrashekara C, Bhatt JC, Kumar A. Comparative genomics and association mapping approaches for blast resistant genes in finger millet using SSRs. PloS one. 2014c;9(6):e99182.

26. Chomczynski P, Sacchi N. Single-step method of RNA isolation by acid guanidinium thiocyanate-phenol-chloroform extraction. Analytical biochemistry. 1987;162(1):156-9.

27. Sambrook J, Fritsch EF, Maniatis T. Molecular cloning: a laboratory manual. Cold spring harbor laboratory press; 1989.

28. Livak KJ, Schmittgen TD. Analysis of relative gene expression data using real-time quantitative PCR and the 2$\Delta \Delta$ CT method. methods. 2001;25(4):402-8. 